\title{
Efektivitas Latih Kandung Kemih Terhadap Percepatan Perkemihan Pada Ibu Pasca Salin
}

\author{
${ }^{1}$ Vera Abdullah, ${ }^{1}$ Jimmy Chandra \\ ${ }^{1}$ Jurusan Kebidanan Poltekkes Kemenkes Sorong
}

\begin{abstract}
ABSTRAK
SDgs targeting in 2030, the global maternal mortality rate can reach 70 per 100.000 live births. In indonesia, bleeding contributes the most maternal mortality and around $16-17 \%$ cases are caused by uterine atony due to urinary retention. Which prevents the uterus from contracting properly because the uterus is pushed up and sideways. Vaginal delivery and worries due to pain result in the inability to excrete urine which can cause complication of uremia, infection, sepsis, an even spontaneous rupture of urinary vesicles. Training bladder 2hours postpartum is one of interventions that can be done so that mother can return to normal urinary pattern and prevent bleeding that results in death. The purpose of this study was measure the effectiveness of bladder training on the acceleration of post partum maternal urination at the Sorong district hospital in 2018. The result of this study we expected to be a reference for complementary therapies to overcome cases of urin retention in post partum mothers. This research method uses a quasi experimental method with a cross sectional approach. The result of hypothesis using kruskal-walls showed a $p$ value $>0,05$, that's mean there was no effectiveness of bladder training on the acceleration of post partum maternal urination at the Sorong district hospital.
\end{abstract}

Key words $\quad$ : urinary retention, post partum, bladder training

\section{ABSTRAK}

Sustainable Development Goals menargetkan pada tahun 2030, AKI secara global bisa mencapai 70 per 100.000 kelahiran hidup. Di Indonesia perdarahan menyumbang AKI terbanyak dan sekitar 16-17\% kasus disebabkan atonia uteri akibat retensi urin sehingga menghambat uterus berkontraksi dengan baik karena uterus terdorong ke atas dan ke samping. Latih kandung kemih 2 jam pascasalin merupakan salah satu intervensi yang dapat dilakukan agar ibu dapat kembali pada pola berkemih yang normal dan mencegah perdarahan yang berakibat pada kematian. Tujuan penelitian ini untuk mengukur efektivitas latih kandung kemih terhadap percepatan perkemihan pada ibu pasca salin di RSUD Kabupaten Sorong Tahun 2018. Metode penelitian ini menggunakan metode quasi eksperimental dengan pendekatan cross sectional dengan uji statistik menggunakan dependen T.Tes. Hasil penelitian menunjukan latih kadung kemih tidak efektiv terhadap percepatan perkemihan pada ibu pasca salin ( $p$ velue $=0.07>0.05)$. Simpulan diharapkan dapat menjadi referensi terapi komplementer untuk mengatasi kasus retensi urine pada ibu paskasalin.

Kata kunci : Retensio Urine; Paskasalin; Latih kandung kemih.

\section{PENDAHULUAN}

Salah satu indokator mengevaluasi keberhasilan kesehatan ibu melalui penurunan angka kematian ibu, di Indonesia berdasarkan data survey penduduk antar sensus tahun 2015 terjadi penurunan AKI menjadi 305 per 100.000 kelahiran hidup di bandingkan pada tahun 2012 namun masih jauh dari target SGDs (Infodatin, 2014). Dalam rentang tahun 2010-2013, perdarahan menyumbang angka terbanyak kematian sekitar 16-17\% kasus yang disebabkan karena atonia uterin akibat terjadinya retensi urine sehingga terjadi distensi kandung kemih dan menghambat uterus berkontraksi dengan baik karena uterus terdorong ke atas dan ke samping (Pribakti, 2006 ; Marmi 2012). Latih kandung kemih merupakan salah satu intervensi yang dapat di terapkan pada ibu paska salin dengan gangguan berkemih sehingga ibu mampu mencapai pola berkemih secara normal (Junizaf, 2005 ; Andi, 2008) yang dapat mencegah terjadinya retensio urine dan berakibat pada perdarahan paska salin.

Studi yang di lakukan pada Rumah Sakit Islam Ibnu Sina Bukit tinggi Tahun 2017 menunjukkan adanya pengaruh bladder training terhadap pengeluaran urine ibu post partum. Dengan Pengelolaan kandung kemih yang baik pada 2 jam pascasalin diharapkan dapat berdampak pada kontraksi uterus yang baik sehingga mampu mencegah terjadinya perdarahan yang berakibat pada kematian 
(Yustini, 2008 ; Marmi 2012 ; Smeltzer \& Bare, 2002). Penelitian ini untuk melihat apakah efektivitas latih kandung kemih terhadap percepatan perkemihan pada ibu pasca salin, tujuan penelitian ini untuk mengukur efektivitas latih kandung kemih terhadap percepatan perkemihan pada ibu pasca salin. Adapun manfaat penelitian sebagai acuan dan referensi dalam pengelolaan ibu 2 jam pasca salin normal dengan gangguan berkemih.

\section{METODE}

Penelitian ini menggunakan desain quasi eksperimental dan pendekatan cross sectional serta rancangan One Shot Case Study. Waktu penelitian dilaksanakan selama 1 bulan yaitu tanggal 1 s/d 30 November 2018. Penelitian ini mengambil lokasi di ruang nifas RSUD Kabupaten Sorong, dengan jumlah sampel sebanyak 30 orang. Adapun sasarannya yaitu ibu 2 jam pasca salin normal, belum berkemih, usia reproduktif ( $15 \mathrm{~s} / \mathrm{d} 49$ tahun) dan bersedia menjadi responden. Prosedur penelitian dilakukan intervensi selam 15 menit dengan cara meletakkan tanggan ibu di bawah air mengalir untuk merangsang ibu berkemih. Pengumpulan data menggunakan lembar observasi percepatan perkemihan. Analisis untuk uji normalitas data menggunakan kolmogorof-Sminorv Test dengan taraf signifikansi 0,05 sedangkan untuk uji homogenitas menggunakan uji $\mathrm{F}$ dengan taraf signifikansi 0,05 . Uji parametrik dilakukan jika data memenuhi syarat untuk dilakukan uji analisa dengan menggunakan uji dependent $T$ Test dengan taraf signifikansi 0,05, namun , jika uji asumsi dasar tidak terpenuhi maka digunakan wilcoxon.

\section{HASIL}

\begin{tabular}{|l|l|c|c|}
\hline No & Waktu berkemih & Jumlah & $\%$ \\
\hline 1 & $<60 \mathrm{~m}$ & 1 & 3.3 \\
\hline 2 & $60-120 \mathrm{~m}$ & 4 & 13.3 \\
\hline 3 & $>120 \mathrm{~m}$ & 25 & 83.3 \\
\hline 4 & Total & 30 & 100.0 \\
\hline
\end{tabular}

Responden penelitian sebanyak 30 orang, sekitar 8 orang $(26,7 \%)$ dalam kategori umur kurang dari 20 tahun, sebanyak 11 orang $(36,7 \%)$ pada kategori usia 20-25 tahun, sebanyak 7 orang $(26,3 \%)$ pada kategori usia 26-
30 tahun dan sebanyak 4 orang $(13,3 \%)$ pada kategori usia 31-35 tahun. Untuk lebih jelasnya

\begin{tabular}{|l|l|c|c|}
\hline No & Umur (Tahun) & Jumlah & $\%$ \\
\hline 1 & $<20$ tahun & 8 & 26.7 \\
\hline 2 & 20 s/d 25 tahun & 11 & 36.7 \\
\hline 3 & 26 s/d 30 tahun & 7 & 23.3 \\
\hline 4 & 31 s/d 35 tahun & 4 & 13.3 \\
\hline & Total & 30 & 100.0 \\
\hline
\end{tabular}

dapat di lihat pada tabel 4.1 di bawah ini :

\section{Tabel 4.1 Distribusi Frekuensi berdasarkan umur}

Responden penelitian memiliki paritas yang bervariasi dari 30 responden, sebanyak 16 orang $(53,3 \%)$ memiliki jumlah paritas 1 , sebanyak 7 orang $(23,3 \%)$ memiliki jumlah paritas 2, sebanyak 4 orang $(13,3 \%)$ memiliki jumlah paritas 3 dan sebanyak 3 orang (10\%) memiliki jumlah paritas 4 . Untuk lebih jelasnya

\begin{tabular}{|l|l|r|r|}
\hline No & Paritas & Jumlah & $(\%)$ \\
\hline 1 & 1 & 16 & 53.3 \\
\hline 2 & 2 & 7 & 23.3 \\
\hline 3 & 3 & 4 & 13.3 \\
\hline 4 & 4 & 3 & 10.0 \\
\hline 5 & Total & 30 & 100.0 \\
\hline
\end{tabular}

dapat dilihat pada tabel 4.2 di bawah ini :

\section{Tabel 4.2 Distribusi Frekuensi berdasarkan Paritas}

Waktu perkemihan dari 30 responden yang diberikan intervensi, sebanyak 1 orang $(3,3 \%)$ mengalami perkemihan kurang dari 60 menit, sebanyak 4 orang $(13,3 \%)$ mengalami perkemihan antara 60-120 menit, dan sebanyak 25 orang $(83,3 \%)$ mengalami percepatan perkemihan lebih dari 120 menit (60\%). Lebih jelasnya dapat dilihat pada tabel 4.3 di bawah ini:

\section{Tabel 4.3 Distribusi Frekuensi berdasarkan Waktu Berkemih}

Sebelum dilakukan uji hipotesa dilakukan uji normalitas data menggunakan KolmogorovSmirnov hasil di dapatkan nilai $\mathrm{p}<0,05$ menunjukkan bahwa data tidak berdistribusi normal, sehingga di gunakan uji Kruskal Wallis untuk melihat efektifitas latih kandung kemih 
terhadap percepatan perkemihan. Hasil uji hipotesa menggunakan Wil coxon menunjukkan bahwa nilai $\mathrm{P}=0,07>0,05$ artinya latih kandung kemih tidak efektiv terhadap percepatan perkemihan pada ibu pascasalin di RSUD Kabupaten Sorong. Untuk lebuh jelasnya dapat di lihat pada tabel 4.4 dibawah ini:

\section{Tabel 4.4 Distribusi Frekuensi berdasarkan Waktu Berkemih}

\begin{tabular}{|l|l|}
\hline Test Statistics $^{\mathbf{a}, \mathbf{b}}$ \\
\hline & Volume Urine \\
\hline df & 2 \\
\hline Asymp. Sig. & .070 \\
\hline
\end{tabular}

\section{PEMBAHASAN}

Berdasarkan hasil uji statistic menggunakan kruskal wallis menunjukkan bahwa nilai $\mathrm{P}>0,05$ yang artinya bahwa tidak adanya efektifitas latih kandung kemih terhadap percepatan perkemihan. Hasil penelitian ini sekaligus membantah hasil penelitian yang pernah dilakukan diRS Dr. Cipto Mangunkusumo tahun 2007 menunjukkan bahwa Bladder training yang dilakukan mulai 2 jam paska salin hasilnya efektif untuk mengembalikan fungsi eliminasi buang air kecil pada ibu postpartum. (Ermiati dkk, 2008).

Hasil penelitian ini sejalan dengan penelitian yang dilakukan oleh kaya, 2015 yang menunjukkan bahwa latih kandung kemih (Blender Training) tidak memberikan hasil yang efektif jika tidak di kombinasikan dengan latihan otot dasar panggul intensitas tinggi (highintensity pelvic floor muscle training/PFMT) dalam terapi gangguan system perkemihan diantaranya inkotenensia urine yang dapat mempengaruhi kualitas hidup wanita (kaya, 2015).

Perbedaan hasil penelitian ini di duga karena ada beberapa factor yang mempengaruhi salah satunya karena responden yang tidak homogen dalam segi paritas karena dalam penelitian ini paritas responden bervariasi mulai dari jumlah paritas 1,2,3 dan 4 sedangkan kejadian retensio urine cenderung lebih tinggi terjadi pada ibu dengan jumlah paritas 1 . Sebuah studi yang dilakukan oleh Yulia I. Nurullah,
2017 yang melibatkan 111 responden menunjukkan bahwa kejadian retensi urin terbanyak pada primipara dan durasi persalinan yang lebih dari 24 jam. (Yulia I. Nurulla. 2017).

Paritas juga secara langsung dapat mempengaruhi terjadinya retensi urine karena adanya perubahan anatomis yang disebabkan oleh persalinan, seperti penurunan kandung kemih akibat dorongan dan nyeri sehingga menyebabkan trauma dasar panggul dan menghambat pengosongan kandung kemih secara normal akibat obstruksi, hilangnya kesadaran bahwa kandung kemih penuh sehingga menyebabkan penghambatan berkemih (Yulia I. Nurulla. 2017).

Selain itu responden secara keseluruhan merupakan ibu dengan persalinan normal, yang memiliki resiko kecil terjadinya retensio urine. Hal ini di sebabkan karena pada persalinan normal tidak mendapatkan anastesi secara epidural. Berbeda pada persalinan sectio caesarea yang menggunakan anastesi epidural sehingga mengakibatkan ketidakmampuan ibu merasakan bahwa kandung kemihnya penuh dan ketidakmampuan memulai atau menghambat berkemih. (F, Navisah, 2015)

Sebuah studi menunjukkan bahwa retensi urine pada paska salin lebih tinggi terjadi pada pasien yang mendapatkan tindakan anastesi epidural, episiotomy dan melahirkan bayi besar. Kemampuan buang air kecil di pengaruhi oleh keadaan perineum yang tidak utuh sehingga ibu takut dan khawatir. Secara umum wanita memang membutuhkan lebih banyak waktu untuk menormalkan pengosongan kandung kemih karena masalah retensi urin, namun sejauh ini belum ada data yang menunjukkan efek jangka panjang dari retensio urine. (Femke E. M. Mulder.et al. 2017)

latih kandung kemih tidak efetiv terhadap percepatan perkemihan bukan berarti tidak dapat dilakukan intervensi untuk kasus retensio urine, karena ada intervensi lain yang dapat dilakukan salah satunya dengan mobilisasi dini. Sebuah studi yang dilakukan pada ibu paska salin dengan sectio caesarea menunjukkan hasil bahwa mobilisasi dini terbukti lebih efektif di bandingkan dengan bladder training dalam pemulihan fungsi eliminasi buang air kecil pertama kali. Hal ini di buktikan dengan adanya 
perbedaan selisih waktu sekitar 14,19 menit. (F, Navisah, 2015).

\section{SIMPULAN}

latih kandung kemih tidak efektiv terhadap percepatan perkemihan pada ibu pascasalin di RSUD Kabupaten Sorong.

\section{SARAN}

Bidan sebagai pemberi asuhan pada ibu nifas dapat mengkombinasikan latih kandung kemih dengan mobilisasi dini atau latih otot dasar panggul tingkat tinggi agar dapat memberikan hasil yang maksimal.

\section{DAFTAR PUSTAKA}

Andi, Retensio Urine Post Partum. Jurnal Kedokteran Indonesia, Volume 20 Februari 2008.

Alkema, L. et al. regional , and national levels and trends in maternal mortality between 1990 and 2015, with scenariobased projections to 2030: a systematic analysis by the UN Maternal Mortality Estimation Inter- Agency Group', The Lancet. World Health Organization. Published by Elsevier Ltd/Inc/BV. All rights reserved., 387(10017), pp. 462-474. doi: 10.1016/S0140-6736(15)00838-7. 2016.

Anggraini dan Yetti. Asuhan Kebidanan Masa Nifas. Yogyakarta:Pustaka Rihama. 2010.

Bahiyatun. Asuhan Kebidanan Nifas Normal. Jakarta : EGC. 2009.

Ermiati, Y. Rustini dkk. 'Efektivitas bladder training terhadap fungsi eliminasi Buang Air Kecil (BAK) pada ibu postpartum spontan. Jurnal Majalah Obstetri Ginekologi Indonesia 206-211. 2008.

Femke E. M. Mulder,et al. Long-term micturition problems of asymptomatic postpartum urinary retention: a prospective case-control study. Int Urogynecol Jurnal. 29:481-488. 2017. 2018

Hidayat \& Uliyah, Keterampilan dasar praktik Klinik untuk Kebidanan Edisi 2. Jakarta Penerbit Salemba Medika. 2008.
Hilda ekasi, dkk. Waktu Pertama Buang Air Kecil (BAK) pada ibu post partum yang dilakukan bladder training. Jurnal Ilmu Kesehatan. Vol.VI,No I, Maret 2014

Junizaf. Penanganan Retensi Urin Pasca Persalinan, Uroginekologi 1 Sub bagian Uroginekologi Rekonstruksi Bagian Obstetri Ginecologi Fakultas Kedokteran Universitas Indonesia. Jakarta.2002

Kementrian Kesehatan Republik Indonesia. Mother's Day: Situasi Kesehatan Ibu. Jakarta : Pusat Data dan Informasi Kementrian Kesehatan RI. 2014.

Marmi.Asuhan Kebidanan pada Masa Nifas "Puerperium Care". Yogyakarta: Pustaka Pelajar. 2012

Navisah,Fitrotun, and Rahayu Astuti. "Perbedaan Efektivitas Mobilisasi Dini Dan Bladder Training Terhadap Waktu Eliminasi Bak Pertama Pada Ibu Post Sectio Caesarea DI RSUD DR. H. Soewondo Kendal." Karya Ilmiah S. 1 Ilmu Keperawatan. 2017

Notoatmodjo \& Soekidjo. Ilmu Perilaku Kesehatan. Jakarta: Rineka Cipta. 2010 Metodologi Penelitian

Kesehatan. Jakarta: Rineka Cipta. 2010

Potter, Patricia A. dan Anne Griffin Perry. Buku Ajar Fundamental Keperawatan.Jakarta: EGC. 2006.

Prawirohardjo,Sarwono. 2009. Ilmu Kebidanan. Jakarta: PT Bina Pustaka Sarwono Prawirohardjo

Pribakti B.2006. Tinjauan kasus Retensi urin postpartum di RS.Unlam/ RS. Dexa Medica.

Profil Kesehatan Indonesia. Data Angka Kematian Ibu (AKI) di Indonesia dan data penyebab kematian ibu. Jakarta: Depkes RI. 2015.

Rakhi Shivkumar,et al. Effects of Bladder Training and Pelvic Floor Muscle Exercise in Urinary Stress Incontinence During Postpartum Period. Indian Journal of Physiotherapy and Occupational Therapy. October Vol.9,No.4. December 2015.

Saleha, Siti. Asuhan Kebidanan pada Masa Nifas. Jakarta: Salemba Medika. 2009. 
Saifuddin, Abdul Bari dkk. Buku Acuan Nasional Pelayanan Kesehatan Maternal dan Neonatal.Jakarta: Yayasan Bidan Pustaka Sarwono Prawiroharjo. 2014.

Saraswati Devi Endah. Efektifitas Bladder Training Sitz Bath Terhadap Fungsi Eliminasi Spontan Pada Ibu Post Partum Spontan. Jurnal Ilmu Kesehatan. 2016.

Saryono. Metodologi Penelitian Kebidanan, Yogyakarta: Nuha Medika. 2011.

Stephansson, O., et al. "Prolonged second stage of labour, maternal infectious disease, urinary retention and other complications in the early postpartum period." BJOG: An International Journal of Obstetrics \& Gynaecology 123. 2016: 608-616. 2016

Yustini,E, dkk.Efektivitas Bladder training terhadap BAK spontan post partum, Majalah Obstetri Ginekologi Indonesia. Vol.32:4. Oktober 2008

Yulia I. Nurulla. Parity and Duration of Labor Affects the Risk of Urinary Retention in post C-Section Patients. Indonesia Jurnal Obstetri Gynecologi ; 37-1: 46-50. 2013

Kaya, Serap, et al. "Short-term effect of adding pelvic floor muscle training to bladder training for female urinary incontinence: a randomized controlled trial." International urogynecology journal 26.2 (2015): 285- 293. 